\title{
Digitalizando a memória de Salvador: nossos presente e passado têm futuro?
}

\begin{tabular}{|c|c|}
\hline \multirow{2}{*}{ Jussara Borges } & $\begin{array}{l}\text { Graduando em Arquivologia pelo Instituto de Ciência da Informação, UFBA; } \\
\text { Bolsista de Iniciaçãao Cientíifica, Pibic/CNPq. }\end{array}$ \\
\hline & $\begin{array}{l}\text { Mestre em Ciência da Informação pelo Instituto de Ciência da } \\
\text { Informação, UFBA. }\end{array}$ \\
\hline \multirow[t]{2}{*}{ Othon Jambeiro } & \\
\hline & $\begin{array}{l}\text { Mestre em Ciências Sociais (USP); Protessor Titular do Instituto de Ciência } \\
\text { da Informaçẫo, UFBA. }\end{array}$ \\
\hline
\end{tabular}

A migração de documentos para o formato digital, mantendo-se intacta a informação, significa mudança profunda no objeto a ser preservado. Cada fonds d'archives' deve ser analisado em sua especificidade, pois nenhum modelo prático é aplicável genericamente. Este trabalho analisa a migração para o formato digital do acervo da Fundação Pierre Verger. Conclui-se que só se alcança a plenitude dessa migração com a criação de redes e sistemas interoperáveis de informações arquivísticas.

Palavras-chave : Preservação digital; Migração de suportes; Fundação Pierre Verger; Documentos digitais; Arquivos digitais; Digitalização de documentos iconográficos.

'Expressão francesa que, em português, convencionou-se traduzir por Fundo de Arquivo e que conceitua "o conjunto de documentos produzidos e/ou acumulados por determinada entidade pública ou privada, pessoa ou família, no exercício de suas funções e atividades, guardando entre si relações orgânicas, e que são preservados como prova ou testemunho legal e/ou cultural, não devendo ser mesclados a documentos de outros conjuntos, gerados por outra instituição, mesmo que este, por quaisquer razões, the seja afim". (BELLOTO, 2004, p. 128). 


\section{Introdução}

Vários eventos importantes estão contribuindo para os estudos acerca da preservação digital, no Brasil e no mundo. Com a publicação do modelo de referência Open Archival Information System (CCSDS-650.0-B- I) e do esforço nacional representado na Carta de Preservação do Patrimônio Arquivístico Digital, da Câmara Técnica de Documentos Eletrônicos do CONARQ, a Arquivologia no Brasil tem a oportunidade de desenvolver um conjunto de conhecimentos científicos sobre o tema preservação digital, que possa ser compreendido dentro da realidade social e econômica brasileira e dentro da linha de conhecimento arquivístico existente.

Algumas vantagens da preservação da informação em estado digital já são conhecidas. Do ponto de vista do usuário, o acesso a fontes de informações digitais se mostra cômodo, pois não requer presença física, podendo ser consultada através de uma rede de computadores como a Internet. Outra vantagem, citada por Michelson e Rothenberg (apud HEDSTROM, 1995) refere-se à possibilidade das redes e o acesso a uma variedade maior de fontes de informações, através do ambiente digital, mudarem as dimensões do processo de trabalho escolar.

A migração de documentos para o formato digital é muito mais do que apenas sua digitalização. Ela pode significar a mudança, talvez profunda, no objeto a ser preservado, quando se procura manter a informação intacta. Esse processo é complexo e muitas vezes caro, tendo-se que buscar alternativas visando à sua viabilização. Exemplo disso é a associação entre entidades destinadas a adquirir os equipamentos necessários, com uso comum. Um consórcio desse tipo permite a divisão do investimento necessário, além de possibilitar que os recursos humanos compartilhem informações e técnicas.

Saliente-se, contudo, que a análise de cada acervo a ser digitalizado é extremamente necessária. Nenhum modelo prático é aplicável genericamente, devendo passar por adaptações indicadas pela natureza das peças do acervo.

Este trabalho faz parte de um estudo que descreve e analisa a migração para o formato digital dos acervos dos arquivos existentes em Salvador, detendose, principalmente, nos que têm natureza pública e, por isso, obrigados a tornarem-se acessíveis a qualquer interessado.

Os objetivos deste trabalho são: conhecer os requisitos essenciais da preservação digital de informações arquivísticas, segundo a OAIS; e conhecer a situação do Arquivo da Fundação Pierre Verger, em Salvador, frente ao processo de migração dos suportes tradicionais para suportes baseados em tecnologias avançadas de informação e comunicação.

Do ponto de vista tecnológico, são avaliadas algumas das condições objetivas que a cidade detém quanto ao uso de técnicas e equipamentos apropriados à preservação digital. São também analisados os recursos humanos dedicados a esta tarefa e sua adequação a ela.

$\bigcirc$ argumento principal do estudo é o de que o desenvolvimento da chamada Sociedade da Informação no Brasil depende da disponibilização crescente de acervos de informações contidos em organizações de toda natureza, particularmente arquivos. Estes têm importância decisiva na preservação da cultura e da identidade nacional, além de serem conjuntos já organizados que, digitalizados e disponibilizados ao acesso público universal, aumentarão a necessária presença da cultura brasileira no fluxo internacional de informações. 
No caso específico de Salvador, universo no qual se situa o trabalho, há preciosos acervos depositados em arquivos públicos e privados, tanto de natureza textual quando de imagens, antigas e modernas, expressas em livros, relatórios, revistas, jornais, fotos, filmes, pinturas, gravuras e diversas outras formas de criação artística, literária, cultural e científica. Esse expressivo acervo depende de trabalho organizado, políticas, diretrizes, modelos técnicos, esforços e recursos de grande porte, para que possa migrar para o formato digital. Este trabalho mostra o estado em que um de seus arquivos mais importantes se encontra - o arquivo da Fundação Pierre Verger -, os resultados conseguidos, e os caminhos que estão sendo trilhados.

\section{Aspectos conceituais}

Segundo Lusenet (apud THOMAZ; SOARES, 2004), após a explosão da produção informacional e a possibilidade de digitalização da informação, a humanidade chegou ao ponto atual, onde $90 \%$ das informações podem ser encontradas em meio digital, grande parte exclusivamente neste ambiente. Segundo esses autores, a ciência se preocupa cada vez mais com a memória que está sendo produzida de forma não-material, codificada em formato binário. Grande parte dessa massa de informações é regida ao sabor da concorrência comercial das organizações, que desenvolvem as tecnologias da informação e comunicação e não têm a preocupação com a formação do patrimônio cultural.

Neste cenário, a International Organization for Standardization ISO - convidou o Consultative Committee for Space Data System CCSDS - para liderar o desenvolvimento de um padrão que pudesse atender às necessidades de um modelo de preservação digital a longo prazo. Criou-se, assim, o Open Archival Information System - OAIS -, um modelo conceitual aprovado pelo CCSDS, que pretende se tornar um referencial para iniciativas de preservação digital.

A análise da situação, o planejamento arquivístico, a disponibilidade de recursos, a aplicação de métodos e tecnologias necessárias para que a informação esteja acessível à comunidade alvo, a longo prazo, a capacidade de manutenção da integridade e acessibilidade da informação, o acesso não-autorizado, a representação, a interpretação da informação e tantas outras variáveis, são preocupações que permeiam a literatura acerca da preservação ou arquivamento digital (HEDSTROM apud THOMAZ; SOARES, 2004; TASK FORCE ON ARCHIVING OF DIGITAL INFORMATION apud THOMAZ; SOARES, 2004).

Outra preocupação é a de alocar recursos humanos preparados com o objetivo de organizar a descrição da informação para uso posterior, que se agrava com falta de terminologia própria para descrever os relacionamentos, tipos de documentos e outros aspectos (BELLOTO, 2004; JARDIM, 1992).

Nota-se que a intenção de preservar documentos digitais a longo prazo não é tarefa simples, pois preservação digital não é um empreendimento de fácil realização. Ações e métodos simplistas estão fadados a expressarem o inútil esforço que foi empreendido. A obsolescência da tecnologia, por exemplo, é um dos fatores que irão por em prova as estratégias e, possivelmente, fará desmoronar as simplórias tentativas de digitalização do documento arquivístico.

Por outro lado, é interessante citar o ponto de vista de Rusbridge (2006), que expõe as preocupações mais referidas na literatura sobre o tema e 
argumenta que o problema da preservação digital não é tão crítico e/ou alarmante, sob certos pontos de vista. Um dos exemplos, que faz parte do que chama de common assertions, or perhaps assumptions, about digital preservation, é sobre o alto custo da preservação digital. $\bigcirc$ argumento, neste exemplo, é que, comparando o custo de preservação de acervos de suportes tradicionais ao da preservação digital, chegar-se-á à conclusão de que preservação digital, na verdade, é uma atividade de baixo custo.

Não obstante toda a complexidade que pode existir durante a criação de uma infra-estrutura de preservação digital, a longo prazo as vantagens são grandes: a agilização no acesso à informação digitalizada, a disseminação de informações a múltiplos e simultâneos usuários em locais distantes, além da disponibilização de acervos arquivísticos que detêm valor documental numérico e qualitativo e que, portanto, justificam uma migração digital para acesso e preservação das informações.

A migração do suporte físico para o suporte digital possui em si potencial para auxiliar planos de preservação de acervos físicos de valor permanente, através da ação de preservação semelhante ao referido pela British Library (2003, p. 65), quando explica que:

[...] o conceito de uma política de substituição como parte de um programa geral de preservação resulta do reconhecimento de que os recursos disponíveis são insuficientes para a conservação física de todos os documentos de um acervo. Implica uma ampliação dos objetivos de qualquer departamento de preservação, de modo que se menciona a preservação do conteúdo intelectual do acervo e de seu formato físico, na medida em que isso se justifica e existem recursos que o permitem.

Talvez a migração digital seja uma das últimas esperanças, se não a única, de se manter a informação arquivística disponível quando alcança sua terceira idade.

Entende-se que há urgente necessidade de conhecimento acerca de planos para preservação digital e que a execução desses planos está condicionada por cenários de limitações orçamentárias a que os sistemas de informação arquivística estão submetidos. Esses fatores configuram uma situação na qual se torna imperioso um planejamento para preservação a baixo custo.

\section{A informação digitalizada e algumas de suas implicações}

Pensar sobre as implicações das informações digitalizadas, a partir de documentos originalmente criados em suportes tradicionais, requer o reconhecimento de que: a) o "documento original é o feito por direta vontade dos autores e conservado na matéria e na forma genuína nas quais foi originariamente emitido" (PAOLI apud REAL DIAZ apud BELLOTO, 2004, p. I06); e b) a migração digital servirá para expandir as formas de acesso à informação ou como forma de preservação possível (BRITISH LIBRARY, 2003, p. 65).

A ação de preservar informações arquivísticas digitalizadas, a longo prazo, confronta-se com várias situações adversas de ordem tecnológica, legal, operacional e, até mesmo, filosófica. Como preservar documentos digitais se 
os recursos computacionais possuem um alto fator de obsolescência? E se os documentos estiverem legalmente impedidos de serem reproduzidos, perderem ou nem chegarem a adquirir seu valor legal no estado digital? Se passarem a necessitar de recursos que podem se tornar cada vez mais escassos, o que se fará?

As questões legais referentes ao conteúdo que será preservado são fatores críticos, visto que um dos principais elementos da estratégia de preservação é disponibilizar os documentos para acesso e reprodução (CORNELL UNIVERSITY LIBRARY, 2003). O conhecimento da legislação que rege os vários tipos de informação e de documentos é forte condicionante da concepção e dos métodos e técnicas do projeto a ser realizado.

A preservação da totalidade da massa documental produzida por algumas organizações, física ou digitalmente, seria um grande peso no orçamento. Por outro lado, sua total eliminação seria um golpe na história. $\bigcirc$ arquivo criado por uma organização não conta apenas sua história, mas, aliado a um conjunto testemunhal composto por informações externas, arquivísticas ou não, constitui memória, cuja extensão pode se revelar surpreendente (BELLOTO, 2004, p. 27I). Não é simples, pois, afirmar a importância histórica futura de nenhum fonds d'archives a partir, apenas, das características e/ou valores atuais de seu produtor e do produto. Lévy (1993, p. I 17) pensa o mesmo, quando diz:

[...] é preciso pensar nos primeiros séculos da escrita na Mesopotâmia, quando ela apenas era empregada para o recenseamento dos rebanhos, para os inventários logo ultrapassados dos palácios e dos templos. Quem poderia ter previsto, nesta época, que signos gravados no barro, recém-ordenados, transmitiriam um dia a ciência, a literatura, a filosofia ou a opinião pública?

Há ainda outro problema levantado por Lévy (1998, p. I |4), que explica quão difícil é compreender uma mensagem fora de seu contexto vivo de produção. Esta consideração para a preservação digital é crítica. Se um conjunto de elementos que foram submetidos a um processo de migração digital para preservação não puder ser auto-suficiente, auto-explicativo e capaz de expressar sua própria razão de existência, o processo é falho. Os instrumentos de pesquisa devem ser bem construídos para que haja recuperação da informação (BELLOTO, 2004, p. 179). A solução aqui se remete à necessidade de uso de um conjunto de metadados, suficientemente completos para essa função (BULLOCK, 1999).

Também se pode pensar que a melhor prática de preservação dessas informações digitalizadas exigirá descrições e especificações detalhadas das tecnologias adotadas, talvez registradas em suportes físicos (BULLOCK, 1999; NATIONAL LIBRARY OF AUSTRALIA, 2003). Isto, objetivando tornar possível a reprodução do ambiente tecnológico adotado para a preservação digital, no sentido de permitir a reconstrução do ambiente para recuperação da informação, caso haja, por quaisquer motivos, inacessibilidade aos equipamentos de acesso. O manual da NLA (apud THOMAZ e SOARES, 2004) salienta esta situação quando diz que é necessário "informar ao usuário, quando aplicável, o que é necessário para representar o objeto pretendido (ou seus elementos essenciais definidos), independentemente de mudanças nas tecnologias de armazenamento e acesso". 
Lévy (1999, p. I I 5) argumenta que "no universo fundado pela escrita, aquilo que deve se manter imutável pelas interpretações, traduções, difusões, conservações, é o sentido". Isto é, num esforço de totalização, a escrita precisa ter sua significação mantida, de forma a possuir relevância em qualquer tempo.

Apesar desta realidade no universo da escrita, Lévy (1999, p. 118) argui que a cibercultura, aquela que surge quando o ser social se relaciona com as novas tecnologias da informação e comunicação ${ }^{2}$, cria um paradigma onde não há mais mensagens fora de contexto. Temos, então, um universal sem totalidade, remetendo à realidade da oralidade, porém "em outra escala e em outra órbita - na medida em que a interconexão e o dinamismo em tempo real das memórias online tornam novamente possível, para os parceiros da comunicação, compartilhar o mesmo contexto”. Ele conclui (LÉVY, I 999, p. I2I) que na esfera digital, chamada por ele de cibercultura, temos "uma outra forma de instaurar a presença virtual da humanidade em si mesma (o universal) que não seja por meio da identidade do sentido (a totalidade)": é o fim das "grandes narrativas totalizantes" (LYOTARD apud LÉVY, 1998).

Toda essa discussão serve para se criar uma consciência de que não é mais apenas o texto que deve ser preservado, mas também os objetos digitais com características que podem estar tão arraigadas em seu contexto que são indissociáveis dele. Não é apenas o suporte físico que deve ser preservado, como fazem muitos dos profissionais da informação responsáveis por acervos tradicionais, que se concentram apenas na longevidade do suporte. "Esse posicionamento não é suficiente no mundo digital ", afirmam Thomaz e Soares (2004). No mesmo sentido, Cook (apud ERLANDSSON, 1997, p. 14) alerta seus colegas com as seguintes palavras:

[...] archivists can no long afford to be, nor to be perceived to be, custodians in an electronic world. We must stop being custodians of things and start being purveyors of concepts. [...] We must stop fearing that new age of increasing demands, ever more records to manage, difficult computer records to cope with, even shrinking resources - that all these spell hopeless gloom - and start believing that traditional archival principles and theories, transformed into the corporate setting of the records creator and appropriately reconceptualised for an

2 Ver Cibercultura, de Pierre Lévy, para mais detalhes.

3 Tradução livre do autor: "o arquivista não pode se dar ao luxo de ser, nem procurar ser, apenas guardião da informação no mundo eletrônico. Devemos parar de ser guardiões das coisas e passarmos a ser fornecedores de conceitos. [...] Devemos parar de temer essa nova era de demandas crescentes, sempre com mais registros para controlar; devemos parar de temer e evitar os registros no computador, cada vez mais difíceis de lidar e com cada vez menos recursos - toda essa mudança pode gerar sentimento de desânimo e abatimento. Devemos começar a acreditar que os tradicionais princípios e as teorias arquivísticas, devidamente contextualizadas para um mundo eletrônico, podem conter a chave da prosperidade no novo ambiente que deveremos agir". electronic world, may hold the key to prospering in the new environment we face. ${ }^{3}$

Tomando como exemplo uma mensagem eletrônica (e-mail), ver-se-á que não se trata de apenas texto em meio digital, não é apenas escrita, mas um objeto digital com um contexto que Ihe dá significado e se torna indispensável à sua compreensão. Deve ser encarada como possuidora de características próprias e distintas, embora seja um elemento de um todo arquivístico indissociável. Uma unidade que forma um todo, que se torna incompleto, enquanto memória, se alguma de suas partes (conteúdo e contexto) for suprimida.

Neste ambiente apresentado, é necessário empreender um esforço investigativo no sentido de reunir conhecimento acerca dos processos de preservação digital. Um pensamento amplo, reconhecendo que a simples digitalização e guarda deve ser fundamentada por princípios que são indispensáveis para a manutenção da informação digitalizada, pelo tempo necessário a que se faça história. 


\section{Requisitos essenciais para a preservação digital, segundo a OAIS}

Bullock (apud THOMAZ e SOARES, 2004), baseando-se nos conceitos do modelo de referência do Open Archival Information System, aponta requisitos mínimos que devem ser observados quando há a necessidade de se empreender recursos para preservar objetos digitais a longo prazo. Eles são citados e comentados a seguir:

- Fixar os limites do objeto a ser preservado: embora a natureza multimídia e hipertextual dos objetos digitais seja bastante vantajosa do ponto de vista da navegação, para fins de preservação é necessário definir, claramente, quais elementos serão efetivamente mantidos.

- Preservar a presença física: a presença física representa o(s) arquivo(s) físico(s), isto é, a camada primitiva de suporte da informação a ser representada; refere-se, portanto, ao(s) arquivo(s) de computador, às séries de zeros e uns que são a base para o significado de um objeto digital.

- Preservar o conteúdo: refere-se a manter a capacidade de acessar o conteúdo em seu nível mais baixo, como um arquivo texto em ASCII, independentemente do estabelecimento de variações de fontes e características de layout.

- Preservar a apresentação: o conteúdo é apresentado visualmente através da aplicação de fontes de diferentes formatos e tamanhos, uso de espaço em branco, colunas, margens, cabeçalhos, rodapés, paginação e assim por diante. Em alguns tipos de documentos digitais (formatos padrão SGML e alguns formatos PDF) as especificações de apresentação ficam separadas do conteúdo.

- Preservar a funcionalidade: objetos digitais podem conter componentes multimídia (texto, gráficos, áudio e vídeo integrados), existir em formato hipertexto (podem desviar dinamicamente para outros pontos do próprio documento ou para outro documento), conter conteúdo dinâmico (gerado automaticamente a partir de bancos de dados) ou ter funções de navegação (barras de ferramentas, pesquisa a palavra-chave ou tabelas interativas de conteúdos).

- Preservar a autenticidade: é necessário confiar em que o objeto acessado é exatamente aquele que se procura e que as possíveis transformações pelas quais passou, para manter sua acessibilidade, preservaram sua forma original.

- Localizar e rastrear o objeto digital ao longo do tempo: imediatamente após a sua criação, os objetos digitais tornam-se passíveis de serem alterados, copiados ou movimentados. Em qualquer referência ao objeto digital, é necessário localizá-lo na edição ou versão correta.

- Preservar a proveniência: identificar a origem de um objeto e detalhar seu histórico ajudam a confirmar sua autenticidade e integridade.

- Preservar o contexto: os objetos digitais são definidos por suas dependências de hardware e software, seus modos de distribuição e relacionamentos com outros objetos digitais. 
Diversos autores tratam de pontos a serem contemplados em um projeto de digitalização, como: critérios de seleção do material, conversão, controle de qualidade da digitalização, gerenciamento da coleção, disponibilização e armazenamento do acervo digital (WAITES apud AMARAL, 2004; CONWAY apud AMARAL, 2004; BROWN apud AMARAL, 2004; OGDEN et al apud AMARAL, 2004; UNESCO apud AMARAL, 2004).

Há necessidade de atenção na preservação do contexto. A arquivologia prevê a descrição dos objetos informacionais, os documentos, como a forma ideal para possibilitar a pesquisa e recuperação posterior das informações registradas, o que é chamado de descrição arquivística. Essa descrição compreende o contexto e o conteúdo do conjunto informacional.

A identidade do acervo é resultado da descrição arquivística, representada pelos vários instrumentos de pesquisa resultantes. A explicitação estruturada e acessível dessa identidade é necessária para a preservação da informação digitalizada, além de ser fundamental que haja homogeneidade do processo de descrição entre instituições distintas, para que seja possível a criação de redes eficientes de instrumentos para o acesso às informações.

O interesse em normalizar o processo de descrição arquivística já resultou em algumas normas, que podem ser um bom caminho na busca pela preservação do contexto de objetos digitais arquivísticos. Para a descrição em si, está disponibilizada pelo Conselho Internacional de Arquivos a Norma Internacional Geral de Descrição Arquivística, ISAD(g). A criação de instrumentos arquivísticos de pesquisa em meio digital já conta com o padrão Encoded Archival Description - Document Type Definition - EAD/DTD - ${ }^{4}$, que permite que instrumentos construídos com a ISAD(g) possam ser codificados para um formato digital, usufruindo de todas as vantagens que as TICs oferecem. O Projeto PLEADE ${ }^{5}$, parcialmente patrocinado pelo Centre Historique des Archives Nationales (França), é um exemplo de como instrumentos codificados pela EAD/ DTD podem ser disponibilizados e utilizados em ambiente web.

A preservação do contexto, também entendida como criação dos metadados, é fundamental para a preservação das informações em meio digital.

\section{Estudo de caso em Salvador A Fundação Pierre Verger}

A Fundação Pierre Verger - FPV - funciona desde 1988 na cidade de Salvador, com a missão de realçar a influência dos países africanos Benin e Nigéria, na Bahia. $\bigcirc$ fotógrafo-etnólogo Pierre Verger doou à Fundação seu arquivo pessoal, que foi se compondo em décadas de viagens e pesquisas. Nesse acervo encontram-se dezenas de artigos, livros, cerca de 62.000 negativos fotográficos, correspondências e outros tipos de documentos.

${ }^{4}$ Mais informações em: http://Mnww.loc.gov/ ead/

A FPV funciona na mesma casa em que Pierre viveu durante anos,

${ }^{5}$ Mais informações em: http://nww. pleade. org gerida por um grupo que é composto por amigos, colaboradores e admiradores da obra de Verger.

A maior parte do arquivo encontra-se na Fundação. As exceções são 
de três ordens:

a) No final dos anos 40, quando Pierre Verger se encontrou com o fotógrafo Marcel Gautherot, no rio São Francisco, em Bom Jesus da Lapa, Bahia, cada um fotografou quatro vezes o outro e trocaram os negativos. Com a aquisição do acervo de Marcel Gautherot pelo Instituto Moreira Salles, sabe-se que quatro negativos de Pierre Verger estão custodiados por esse Instituto. Os quatro negativos produzidos por Gautherot e recebidos por Verger, se encontram na própria FPV.

b) A FPV identificou em publicações contemporâneas de Pierre Verger, cerca de 100 imagens do fotógrafo, porém os negativos dessas imagens não se encontram na Fundação e sua localização é desconhecida.

c) $\bigcirc$ próprio Pierre Verger afirmou ter perdido vários negativos durante a II Guerra Mundial, porque foram acondicionados em local úmido, deteriorando-se em seguida.

Todo o acervo arquivístico da FPV foi tratado por Anne Baradel, francesa, formada em Arquivística pela Universidade de Montreal (Canadá) e Mestre em Multimídia pela Universidade de Paris 8 (França). $\bigcirc$ trabalho arquivístico dos negativos foi executado em seis meses, durante o ano de 2000 e se manteve fiel à organização dada por Verger. As peças estão organizadas de acordo com a localização geográfica da imagem da foto. O website da FPV é mantido por Anne Baradel.

O estudo exploratório para este trabalho foi realizado através de visitas à Fundação, visando a conhecê-la e aos métodos de migração para o meio digital, através de entrevistas com Alex Baradel, um dos responsáveis pelo departamento de Acervo e Direitos Autorais. De origem francesa, Baradel chegou à Fundação como funcionário de uma empresa que produzia CDROM multimídia. Seu interesse por fotografia, e posterior interesse pela obra de Verger - ao cabo do trabalho de digitalização de várias ampliações do acervo fotográfico - acabaram por levar a Fundação a admiti-lo em seu quadro funcional. As informações a seguir foram fornecidas por ele, salvo as exceções explicitadas.

Em 200I, a FPV decidiu criar um website (http:// www.pierreverger.org) para divulgar melhor a obra do fotógrafo. Nesse site encontram-se 5.700 fotografias do total da obra. Essas peças foram digitalizadas em baixa resolução, entre os anos de 1999 e 2001 e pretendem permitir ao visitante uma noção da obra de Verger. As peças não podem ser consideradas produtos de um processo de preservação digital, visto que não podem substituir os originais físicos.

A FPV possui atualmente cerca de 6.500 negativos digitalizados, em duas configurações: 2000 dpi x 2000 dpi, que permitem a reprodução no tamanho máximo de $18 \mathrm{~cm} \times 18 \mathrm{~cm}$ e 2500 dpi × 2500 dpi. É possível fazer também reproduções de $22 \mathrm{~cm} \times 22 \mathrm{~cm}$, a 300 dpi.

Para um processo ideal de digitalização dos negativos, com fins de preservação, a FPV, segundo Baradel, considerou que era necessário um scanner com capacidade de reconhecimento de uma ampla gama de cinzas. A densidade da imagem deve ser reconhecida com o máximo de precisão, sob pena de prejudicar a qualidade da reprodução posterior. $\bigcirc$ tamanho máximo das ampliações e o tempo necessário para a digitalização e manipulação do documento digital devem ser pontos importantes a se considerar. Caso a 
digitalização de uma única peça demore cerca de duas horas, o tempo necessário para digitalizar um grande acervo pode ser desanimador.

Além do tempo, o espaço de armazenamento também deve ser observado, visto que pode se tornar muito grande. No estudo de caso do Arquivo Público da Cidade de Belo Horizonte, foram indicados entre 700 e $900 \mathrm{MB}$ de tamanho para uma imagem digital obtida de um negativo, isso com apenas 50\% da resolução da imagem original (AMARAL, 2004). Caso todo o acervo da FPV fosse digitalizado sob essas configurações, seriam necessários cerca de 48.438 GB em capacidade de armazenamento, algo em torno de I 0.306 mídias de DVD-R com capacidade para 4.7 GB cada.

Em Salvador, segundo Baradel, o máximo de capacidade de digitalização e reprodução, através de empresas especializadas, está em torno de $1 \mathrm{~m}^{2}$ a 300 dpi. A qualidade da reprodução é tão crítica para a Fundação que as ampliações são feitas no Rio de Janeiro e São Paulo e não na própria cidade onde está a Fundação.

Existem negociações, ainda não formalizadas, para digitalização de todos os negativos do acervo, visando à preservação da obra de Verger. $\bigcirc$ plano prevê seu início para após a conclusão do processo de restauração dos negativos, que se iniciou em novembro de 2004. Há a probabilidade do profissional responsável por essa digitalização ser o mesmo que será treinado e contratado para execução de um projeto de conservação dos negativos. Da parte da FPV, não há qualquer política ou planejamento formal para a migração digital. Até esse momento, todo o processo parece depender da experiência e/ou planejamento da parte do corpo funcional do Instituto Moreira Salles.

A FPV está fazendo um primeiro investimento com o intuito de preservar seu patrimônio. Um anexo está sendo construído na sede com a infra-estrutura necessária para acondicionar os negativos. A antiga sala onde se localizavam os negativos será reformada para servir de laboratório para avaliação das peças e realização de restaurações simples. Peças com problemas complexos deverão ser separadas e encaminhadas a um laboratório especializado.

Dentre as características que a FPV considera necessárias e/ou essenciais para a digitalização, visando à preservação no longo prazo, estão:

a) Os documentos digitais gerados devem ter boa qualidade, chamando a atenção para as nuances de cinza das imagens;

b) Deve-se ter cuidado com o tempo de digitalização e tamanho final dos documentos digitais (o que remete à resolução escolhida);

c) $\bigcirc$ trabalho de retoque deve ser realizado por um profissional de sensibilidade artística;

d) Deve haver cuidado quanto à definição do suporte mais seguro para armazenamento e backup dos documentos digitais.

Em suma, a FPV possui funcionários com visão do valor do acervo. Isso é importante, pois a partir daí pode-se esperar que não haverá negligência consciente no tratamento dos documentos. Essa mesma visão é que leva a Fundação a buscar auxílio externo para a migração digital, por entender que não possui meios próprios para realizar tal processo.

A ação da FPV em buscar auxílio externo reforça o ponto da Carta para a Preservação do Patrimônio Arquivístico Digital, que afirma ser necessário promover ações cooperadas entre instituições. Dificilmente cada instituição arquivística no País tem a capacidade de promover sozinha uma iniciativa de migração digital. 


\section{Considerações finais}

O Livro Verde da Sociedade da Informação no Brasil (TAKAHASHI, 2000) discorre sobre a necessidade de facilitar o acesso aos acervos culturais nacionais, disponibilizando-os através da Internet.

O futuro da Sociedade da Informação no Brasil depende do desenvolvimento da ampliação da infra-estrutura de conectividade e dos conteúdos disponíveis a serem acessados. Um dos atores apontados com papel estratégico nesse processo são os arquivos, que podem viabilizar tanto o acesso público e gratuito à rede internacional, transformando-se em pontos de acesso, como a publicação de conteúdos na rede, a partir de seu acervo.

Além disso, o Livro Verde propõe o estabelecimento de normas técnicas para o tratamento de conteúdos, a fim de garantir maior racionalidade nos processos de armazenamento e maior pertinência e relevância na recuperação de informações, considerando os níveis e limitações dos grupos de usuários interessados.

Os requisitos essenciais da OAIS parecem oferecer os principais elementos a serem considerados no estabelecimento desses métodos e normas para a preservação digital. Ressalve-se, contudo, ser sempre necessário realizar estudos específicos para aplicar esses princípios aos acervos arquivísticos.

O tamanho das imagens digitais geradas a partir de acervos fotográficos torna-se grande quando as imagens possuem fins de preservação, já que a resolução deverá ser elevada. Isso demanda um investimento inicial e de manutenção que nem todos os arquivos podem fazer.

Em Salvador, essa migração dos acervos começa a ser realizada, tanto em arquivos privados quanto públicos. No estudo de caso apresentado - da Fundação Pierre Verger - deve-se considerar que o acervo se constitui no seu maior patrimônio, do ponto de vista econômico, de modo que é natural a existência de alto grau de preocupação, que acabou por levá-la a buscar outra instituição para auxiliar no processo migratório. Em termos de recursos humanos, aquela organização parece estar preparada e atenta às especificidades necessárias para uma preservação digital efetiva do acervo.

Em suma, a migração dos suportes tradicionais para outros, baseados nas novas tecnologias de informação e comunicação, visando à preservação da informação arquivística é hoje uma meta de quase todos os arquivos públicos e privados. As desvantagens enfrentadas no momento, como a rápida obsolescência das tecnologias, tornam-se pequenas se comparadas às vantagens oferecidas pelo ambiente digital, como a possibilidade de permitir acesso a múltiplos e distantes interessados, além da preservação do patrimônio histórico da Humanidade.

É necessário, entretanto, criar redes e sistemas de informações arquivísticas que adotem métodos, normas e tecnologias padronizadas ou interoperáveis, para permitir a recuperação das informações contidas em acervos fisicamente dispersos, por meio de uma interligação virtual. 


\section{Digitalizing the memory of Salvador. Do our present and past have future?}

The migration of documents to the digital format means deep change in the object to be preserved. Each fonds d'archives must be analyzed in its specificity, therefore no practical model is applicable generically. This work analyzes the migration of the archival collections of the Pierre Verger Foundation to digital format. The conclusion suggests that migration of documents needs the creation of web networks and compatible archival information systems to be successful.

Key-words: Digital preservation; Medium migration; Pierre Verger Foundation; Digital records; Digital archives; Paper records; Digitizing photographic archives; Salvador; Bahia; Brazil.

\section{Referências}

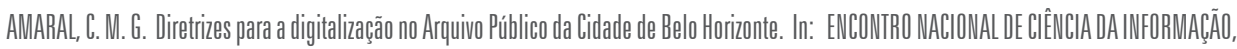

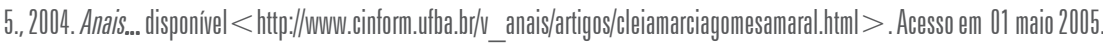

BELLOTO, H. L. Arquivos permanentes: tratamento documental. 2. ed. rev. e ampl. Rio de Janeiro: FGV, 2004.

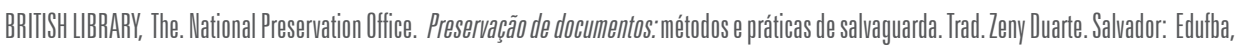
2003.

BULLCKK, Alison. Preservation of digital information, issues and current stattus. 1999. Disponivel em: < hitpp///www.n.Ic-.hnc.ca/publications//1p1-259e.html>. Acesso em 25 nov. 2003.

CORNeLl UNIVERSITY LIBRARY. Moving theory into practice: Digital imaging tutorial. 2003. Disponivel em: <http:/l www.library.cornell.edulpresenvationt|tutoriallindex.httml> Acesso em 15 jun. 2004.

ERLANDSSON, A. Electronic records management. a literature review. Studies - Études 10. International Council on Archives, 1997.

HEDSTROM, M. Digital preservation: a time bomb for Digital Libraries. In: Reconnecting Science and Humanities in Digital Libraries, 1995. Disponivel em: $<$ http://www..uky.edu/ kiernan/DL/symp.html > . Acesso em 5 ago. 2004.

JARDIM, José Maria. A arquivologia e as novas tecnologias da informação. Estudos Históricos, Rio de Janeiro, v. 5, n. 10, p. 251-60, 1992.

LÉVY, P. As tecnologias da inteligência: o futuro do pensamento na era da informática. Tradução de Carlos Irineu da Costa. Rio de Janeiro: Editora 34, 1993. LÉvY. Cihercultura. Trad. Carlos Irineu da Costa. São Paulo: Editora 34, 1999.

NATIONAL LIBRARY OF AUSTRALLA. Guidelines for the preservation of digital heritage. 2003. Disponivel em: < http://unesdoc.unesco.org/images/0013/ 001300/130071e.pdf > . Acesso em 16 jun. 2004.

RUSBRIDGE, C. Excuse Me... Some Digital Preservation Fallacies? 2006. Disponivel em: < httpp://wwww.ariadne.ac..uk/issue46/rusbridge/ > . Acesso em 7 fev. 2006 .

TAKAHASHI, Tadao (Org.). Sociedade da Informação no Brasil. liuro verde. Brasilia: MCT, 2000. cap. 1. Disponivel em < http.//wwww.socinfo.org.br/ livro_verde/download.htm > Acesso em 3 jul. 2003.

THOMAZ, K. P.; SOARES, A.J. A preservação digital e o modelo de referência Open Archival Information System (OAIS). DataGramaZero: Revista de Ciência da Informação. v. 5, n. 1, 2004. Disponível em: < http://wwww.dgz.org.br/feuO4/Art__1.htm>. Acesso em 7 jun. 2004. 